\title{
Spatial scale and species identity influence the indigenous-alien diversity relationship in springtails
}

\author{
Aleks Terauds, ${ }^{1,3}$ Steven L. Chown, ${ }^{1}$ And Dana M. Bergstrom ${ }^{2}$ \\ ${ }^{1}$ Centre for Invasion Biology, Department of Botany and Zoology, Stellenbosch University, \\ Private Bag X1, Matieland 7602 South Africa
2 Australian Antarctic Division, Department of Sustainability, Environment, Water, Population and Communities, \\ 203 Channel Highway, Kingston 7050 Australia
}

\begin{abstract}
Although theory underlying the invasion paradox, or the change in the relationship between the richness of alien and indigenous species from negative to positive with increasing spatial scale, is well developed and much empirical work on the subject has been undertaken, most of the latter has concerned plants and to a lesser extent marine invertebrates. Here we therefore examine the extent to which the relationships between indigenous and alien species richness change from the local metacommunity to the interaction neighborhood scales, and the influences of abundance, species identity, and environmental favorability thereon, in springtails, a significant component of the soil fauna. Using a suite of modeling techniques, including generalized least squares and geographically weighted regressions to account for spatial autocorrelation or nonstationarity of the data, we show that the abundance and species richness of both indigenous and alien species at the metacommunity scale respond strongly to declining environmental favorability, represented here by altitude. Consequently, alien and indigenous diversity covary positively at this scale. By contrast, relationships are more complex at the interaction neighborhood scale, with the relationship among alien species richness and/or density and the density of indigenous species varying between habitats, being negative in some, but positive in others. Additional analyses demonstrated a strong influence of species identity, with negative relationships identified at the interaction neighborhood scale involving alien hypogastrurid springtails, a group known from elsewhere to have negative effects on indigenous species in areas where they have been introduced. By contrast, diversity relationships were positive with the other alien species. These results are consistent with both theory and previous empirical findings for other taxa, that interactions among indigenous and alien species change substantially with spatial scale and that environmental favorability may play a key role in explaining the larger scale patterns. However, they also suggest that the interactions may be affected by the identity of the species concerned, especially at the interaction neighborhood scale.
\end{abstract}

Key words: biological invasions; Collembola; density; environmental favorability; invasion paradox; Macquarie Island, Australia; species identity; species richness; subantarctic.

\section{INTRODUCTION}

How biological invasions proceed in a heterogeneous setting is a question of much significance. Invasions not only have considerable effects on ecosystem structure and functioning (Mack et al. 2000, O'Dowd et al. 2003), but they may also lead to substantial impacts on individual species (Blackburn et al. 2004, McGeoch et al. 2010). Moreover, the establishment of alien species shows no signs of decline, and increasing trade and globalization suggest that species transfers will continue (Hulme 2009).

Much progress has been made in understanding the processes that enable the barriers to invasion to be

Manuscript received 17 November 2010; revised 31 January 2011; accepted 1 February 2011. Corresponding Editor: D. A. Wardle.

${ }^{3}$ E-mail: aleks.terauds@gmail.com crossed (Richardson and Pyšek 2006, Blackburn et al. 2009, van Kleunen et al. 2010). In particular, wide appreciation now exists of the influence on the invasion process of spatial and temporal heterogeneity in a community context (Sax and Gaines 2003, 2008, Davies et al. 2005, Kumar et al. 2006, Melbourne et al. 2007). Several theoretical and empirical studies of the processes by which species (alien or indigenous) establish and coexist in communities have shown that spatial and temporal dynamics, and species identity are important, both in affecting the colonization process and in modifying the extent to which colonizing species might have an impact on residents and the resident community (e.g., Chesson and Warner 1981, Shea and Chesson 2002, Diez et al. 2008, Orrock and Witter 2010, Orrock et al. 2010). In the case of biological invasions it appears that spatial heterogeneity may largely be responsible for the scale dependence of the relationship between indigenous and alien diversity, and that spatial scale 
may in turn influence the extent to which biotic resistance and the identity of species in the receiving community are recognized as major influences on the invasion process (Davies et al. 2005, Melbourne et al. 2007, Diez et al. 2008).

Recent theoretical reviews and meta-analyses of the empirical data have suggested that the invasion paradox, or the change in the relationship between the richness of alien and indigenous species from negative to positive with increasing spatial scale, may largely be an outcome of changes in the heterogeneity of environments (Fridley et al. 2004, 2007, Herben et al. 2004). Community dynamics in homogeneous local environments are prone to be dominated by processes that promote negative relationships between resident and colonizing species, whereas at broader scales, habitat heterogeneity and metacommunity dynamics lead to positive relationships (Melbourne et al. 2007). The scale dependence of the indigenous-alien richness relationship may also be affected by variation in favorability of the environment, and by environmental heterogeneity and biotic facilitation even at small spatial scales (Davies et al. 2007).

Although it may appear that much data now exist on the extent to which richness relationships among indigenous and introduced species vary with spatial scale, the generality of scaling explanations for the invasion paradox has not been broadly established. The majority of work has concerned terrestrial vascular plants (Herben et al. 2004, Levine et al. 2004) and to a lesser extent marine invertebrates (Stachowicz et al. 2002). For other taxa, a positive relationship between indigenous and alien species richness has frequently been recorded at larger spatial scales (e.g., Chown et al. 2005, Evans et al. 2005, Borges et al. 2006), but it is not clear whether this relationship changes at small spatial scales, nor whether it is influenced by environmental favorability. Indeed, Fridley et al. (2007) argued that "observational evidence still lags behind advances in theory."

Therefore, here we investigate explicitly the extent to which the relationship between the diversity of indigenous and alien invertebrates varies at site and sample scales equivalent to the "interaction neighborhood" and "local metacommunity" of Melbourne et al. (2007), and how the relationships might further be modified by changing favorability along an altitudinal gradient. We focus not only on relationships between indigenous and alien species richness at these spatial scales, but also on relationships between abundance (measured as density) among these two groups of species and on relationships among richness and abundance. Understanding variation in the abundance of indigenous and alien species can provide important additional perspectives on the scale dependence of species invasions (Diez et al. 2008). Springtails are used as the exemplar group because of their ubiquity in terrestrial ecosystems (Hopkin 1997) and significance in soil ecosystem functioning (Wardle et al. 2004). We worked on an island system (the subantarctic Macquarie Island) for two reasons. First, the island's isolation means that regional metacommunity processes (see Melbourne et al. 2007), which we do not consider, are likely to proceed at rates much lower than processes at the other two, smaller scales. Second, both indigenous and alien springtail species are present on the island and are relatively well known taxonomically (Greenslade 2006).

\section{Materials And Methods Site description}

Macquarie Island $\left(54^{\circ} 30^{\prime} \mathrm{S}, 158^{\circ} 57^{\prime} \mathrm{E}\right)$ is a small island $(34 \times 5.5 \mathrm{~km})$ located $1500 \mathrm{~km}$ southeast of Tasmania, Australia. An ophiolite complex that has never been attached to another land mass, it has steep coastal slopes rising to an undulating plateau ranging between 150 and $300 \mathrm{~m}$ above sea level (maximum height $433 \mathrm{~m}$ ). The cool, moist, and windy maritime climate is typically subantarctic. Mean annual temperature range is $3.8^{\circ} \mathrm{C}$ to $6.6^{\circ} \mathrm{C}$, with a considerable altitudinal decline in microhabitat temperatures, though with limited seasonal and diurnal ranges, and annual precipitation is $\sim 954 \mathrm{~mm}$ (Tweedie and Bergstrom 2000, Pendlebury and Barnes-Keoghan 2007). Between 1994 and $2003 \sim 312$ frost-free days occurred each year at sea level, declining with increasing altitude to $\sim 185$ frostfree days at $200 \mathrm{~m}$ altitude (Loffler 1983; Australian Bureau of Meteorology, unpublished data).

Tall coastal and slope vegetation occupies $\sim 20 \%$ of the island's surface and is dominated by the megaherbs Stilbocarpa polaris and Pleurophyllum hookeri and the tussock grass Poa foliosa. Short grasses, small herbs, and sedges dominate the mid-altitude vegetated plateau, and form the most widespread communities, covering over $60 \%$ of the island. Fernbrake is restricted to relatively small pockets in steep-sided gullies and more sheltered areas, primarily on the east coast. At higher altitudes feldmark communities predominate, covering $\sim 45 \%$ of the upland area over $180 \mathrm{~m}$, with the cushion plant Azorella macquariensis being dominant. Bryophytes occur in most habitats, being least abundant in tall tussock grassland and fernbrake and most abundant in feldmark communities where they often co-dominate with A. macquariensis (Selkirk et al. 1990, Selkirk and Adamson 1995, Seppelt 2004). Most of the coastal terraces, coastal slopes, and mid-altitude ridges are covered in peat soils of varying depth, with basaltic sand beaches around the coast and mineral rocky soils at higher altitudes.

The island has recently gained some prominence owing to the impacts of rabbits on the terrestrial vegetation, following the eradication of feral cats (Bergstrom et al. 2009). Importantly, the sampling described here was undertaken in 2001/2002, soon after the eradication of the cats and, more significantly, prior to the substantial increase in rabbit abundance and concomitant effects on the vegetation (Bergstrom et al. 2009). 


\section{Sampling}

The primary aims of this study are to investigate the scale dependence of the relationships between indigenous and alien diversity (richness and abundance) and how these relationships might be influenced by environmental favorability (Davies et al. 2007), and perhaps by other environmental factors. Therefore a range of sites was sampled across the island including all of the major vegetation types and a range of altitudes. Increasing elevation served as a proxy for declining environmental favorability because temperature, which among the microclimate variables shows one of the largest consistent changes (declines) with elevation (Tweedie and Bergstrom 2000), has such a profound effect on springtail life histories and abundance (Peterson and Luxton 1982, van Straalen 1994).

Nine widespread, structurally different vegetation types (hereafter termed habitats) were identified for sampling based on previous vegetation classifications (Selkirk et al. 1990). These were: Azorella maquariensisdominated open cushion areas (mean altitude $261 \mathrm{~m}$ ); Acaena spp.-dominated herbfield (mean altitude $43 \mathrm{~m}$ ); Colobanthus muscoides-dominated coastal cushion areas (mean altitude $13 \mathrm{~m}$ ); Pleurophyllum hookeri-dominated herbfield (mean altitude $72 \mathrm{~m}$ ); Poa foliosa-dominated tall tussock grassland (mean altitude $52 \mathrm{~m}$ ); Polystichum vestitum fernbrake (mean altitude $50 \mathrm{~m}$ ); short grassland (dominated by Agrostis magellanica, Festuca contracta, and Luzula crinita, mean altitude $71 \mathrm{~m}$ ); Stilbocarpa polaris-dominated herbfield (mean altitude $43 \mathrm{~m}$ ) and mires (mean altitude $150 \mathrm{~m}$ ).

Five $2 \times 2 \mathrm{~m}$ sites were randomly located for each habitat except for Polystichum vestitum fernbrake where four sites were established. Sites were established at a range of altitudes and away from human influences (such as that of the station, huts, and walking tracks). Due to the nature and occurrence of the habitats being sampled, $70 \%$ of sites were $<100 \mathrm{~m}$ in altitude with mire, Azorella, and short grassland habitats comprising all of the sites $>100 \mathrm{~m}$. Coastal Colobanthus habitats were the lowest sites, all being $<20 \mathrm{~m}$ altitude. Rabbit-grazed and alien plant-dominated areas were avoided. Sites were restricted to homogeneous areas where only one habitat was present. Two random samples were taken from each site using a $70 \mathrm{~mm}$ diameter O'Connor split corer to a soil depth of $70 \mathrm{~mm}$. To account for temporal variation (which tends to be small in the region; see Convey 1996, Barendse and Chown 2001), sampling was repeated four times throughout the study between October 2001 and March 2002 at approximately 5-6 week intervals. Thus 32 samples were collected from the four Polystichum sites and 40 samples were collected from each of the other habitats. Given the relatively short dispersal distances characteristic of most springtails (Hopkin 1997), and the relatively fine-scale vegetation heterogeneity on Macquarie Island (Selkirk et al. 1990), the site scale $(2 \times 2 \mathrm{~m}$ quadrat $)$ was considered the local metacommunity and the individual samples $(70 \mathrm{~mm}$ core) the interaction neighborhood. These scales are consistent with both field observations and manipulative experiments, which have demonstrated that springtails occur in well-mixed assemblages over small distances (i.e., sub-meter distances, such as the sample scale here), and are also able to disperse and interact with each other over larger distances (i.e., many meters, as in the site scale here) (Ponge et al. 2008, Starzomski et al. 2008, Auclerc et al. 2009). Moreover, site-based structure in springtail assemblage data from a similar subantarctic island landscape, sampled in a similar spatial arrangement (Gabriel et al. 2001), suggests that the sites can appropriately be considered the local metacommunity scale. Therefore, our choice of distances for the two scales is consistent with the original descriptions of these scales by Melbourne et al. (2007).

Invertebrates were extracted from the soil cores into propylene glycol using a high gradient extractor (HG). Following Gabriel et al. (2001), the HG was left running at $25^{\circ} \mathrm{C}$ for the first two days then set at $30^{\circ} \mathrm{C}$ for the third and fourth days. Samples were transferred to $100 \%$ alcohol by draining off the propylene glycol through a $60-\mu \mathrm{m}$ mesh. All soil invertebrates were then rinsed off or removed from the mesh with a fine paintbrush and stored in $100 \%$ alcohol for later analyses. Springtails were then separated, and identified using Greenslade's (2006) key, in conjunction with other keys (e.g., Deharveng 1981) in the case of taxonomic uncertainty. Individuals were identified to the species level in most cases, but due to ongoing revision of species (Greenslade 2006), four morphospecies could only be identified to genus. One group (Family Katiannidae) occurred in comparatively low numbers across all samples, and was only identified to family level due to taxonomic uncertainty among some species.

\section{Data analysis}

Because the outcome of any analysis of richness is dependent on sampling adequacy, the latter was estimated at the site scale, for each vegetation type, using EstimateS (version 8.2.0; Colwell 2006). Rarefaction curves were calculated using the Mau Tau momentbased interpolation method. Sampling is considered to be adequate if the rarefaction curve approaches an asymptote. Species richness was calculated using the Jacknife2 estimator (Magurran 2004). Two different estimates are presented. The first was obtained without resampling and provides more accurate estimates of richness, though the generated values are dependent on the original data, and no variance is provided for richness estimates (Colwell 2006). A second estimate was obtained using 500 randomizations and sampling with replacement. This method is more appropriate for the comparisons of data sets (Colwell 2006) and was used to estimate the extent to which observed richness (used to compare outcomes at the interaction neighborhood and local metacommunity scales) served as a reasonable proxy for actual richness. 
Local metacommunity scale.-To investigate the relationship between density (log-transformed) and habitat type and altitude, and between species richness and these environmental variables, a range of modeling techniques was used (implemented in Spatial Analysis in Macroecology version 3.1; Rangel et al. 2006). It should be noted that density is used here as a measure of abundance. Because the sample unit size (soil core) is consistent across all habitats, no confounding census area effect is expected (Gaston et al. 1999). Initially, $\log _{10}(x+1)$-transformed density from (1) indigenous species (DIS) and (2) alien species (DAS) was used as the response variable in ordinary least squares (OLS) models containing the predictor variables: vegetation type (one of the nine vegetation types), altitude (height above sea level in meters) and a squared altitude term (to identify any curvilinear relationships). These three predictor variables resulted in seven possible models, which were sorted in accordance with corrected Akaike's Information Criterion $\left(\mathrm{AIC}_{\mathrm{c}}\right)$ values, and $\mathrm{AIC}_{\mathrm{c}}$ weights were used to choose the best model in each case (Burnham and Anderson 2002).

To account for spatial autocorrelation the same predictor variables were then tested in spatial autoregressive (SAR) models and geographically weighted regression (GWR) models. The likely confounding effects of spatial autocorrelation and the most appropriate methods to account for it have been the subject of much discussion and modeling development recently (for an introduction see Beale et al. 2007, 2010, Begueria and Pueyo 2009, Bini et al. 2009). SARs differ from the OLS models in that they utilize a generalized least squares (GLS) approach that incorporates spatial structure directly in model residuals (Beale et al. 2010) to estimate regression coefficients. Here, the values of the SAR covariance matrix were modeled using a semivariogram function (Banerjee et al. 2004), which has been shown to be reliable (Begueria and Pueyo 2009).

However, a further complication with spatial analyses may arise if the spatial relationship between the response variable and its predictor(s) varies across the entire region under study. This variation is known as nonstationarity, and geographically weighted regression (GWR) models were developed to clarify these complex spatial structures in data at multiple scales (Fotheringham et al. 2002). Although these models may not generalize well beyond the area of study, their ability to account for more complex spatial structure make them a useful tool in clarifying relationships among variables (e.g., Foody 2004, Bini et al. 2009; see also discussion between Foody 2005 and Jetz et al. 2005). Here the geographical weighting was implemented using a Gaussian spatial kernel function with bandwidth selected using a golden search algorithm to optimize the $\mathrm{AIC}_{\mathrm{c}}$ values (Rangel et al. 2006). The best model(s) (from OLS, SAR, and GWR approaches) were selected using the $\mathrm{AIC}_{\mathrm{c}}$ values and weights (Foody 2005, Jetz et al. 2005). Approximate likelihood ratio tests, based on the $F$ test were also used to measure the gain in fitting a GWR model instead of an OLS model, and thus to estimate the amount of nonstationarity in the data (Fotheringham et al. 2002, Bini et al. 2009).

Next, to investigate the relationships between indigenous and alien richness and density at this scale, while accounting for variation owing to altitude and vegetation type, several models were implemented (again including OLS, SAR, and GWR approaches). First, the extent to which indigenous species richness and density (for the logic thereof see Diez et al. 2008) influence the density of alien species (DAS) and richness (ASR) at this scale were investigated. For DAS as the response variable, the predictor variables included were altitude, vegetation type, density of indigenous species (DIS), an interaction term of DIS with vegetation (DIS $\times$ VEG) (given strong habitat associations identified in initial analyses, not shown), and indigenous species richness (ISR). The same set of predictor variables was used to select the best models with alien species richness (ASR) as the response variable. Squared terms of all non-categorical variables were also included in each model selection process. In total, eight predictor variables were used for the models, resulting in 255 possible different models.

Interaction neighborhood scale.-To test the hypothesis that relationships between log-transformed density, richness, and environmental variables change at different spatial scales, the same set of response and predictor variables were tested using log-transformed density data and species richness data from each core sample $(n=350$ cores because two cores contained no springtails). Again, OLS, SAR, and GWR models were tested and $\mathrm{AIC}_{\mathrm{c}}$ values and weights used to select the best models in SAM 3.1 (Rangel et al. 2006).

\section{RESUlts}

\section{Sampling and diversity}

Rarefaction curves for all of the habitats at the site scale indicated that sampling had either reached or was approaching an asymptote (Appendix A). In consequence, sampling was considered adequate for the modeling undertaken here. While the observed species richness values (Sobs) were always lower than the Jacknife2 estimators, they were all well within the variance of the randomized estimates. Species varied substantially in their densities among habitats (Appendix B), with the extent of habitat preference apparently being more pronounced in the indigenous than in the alien species. Overall, springtail species richness was highest in tall tussock and Colobanthus habitats, and lowest in short grassland and Azorella habitats (Appendix B). Tall tussock and Stilbocarpa had the highest mean density of individual springtails while Azorella had the lowest, followed by Polystichum habitats. Stilbocarpa and Acaena sites had the highest density of alien species while Azorella sites had few aliens. 



FIG. 1. (a, b) Log-transformed springtail (Collembola) density (originally measured as no. $/ \mathrm{m}^{2}$ ) vs. altitude (m) of (a) indigenous and (b) alien species on Macquarie Island, Tasmania, Australia. (c, d) Species richness vs. altitude (m) of (c) indigenous springtails and (d) alien springtails. (e, f) Log-transformed density (originally measured as no. $/ \mathrm{m}^{2}$ ) of alien vs. indigenous springtails in (e) mire and (f) Colobanthus-dominated habitats. Coefficients of determination $\left(R^{2}\right)$ and $P$ values are taken from the geographically weighted regressions.

\section{Local metacommunity scale}

Density of the indigenous species was most strongly related to altitude, in a curvilinear, declining fashion (Fig. 1a), with vegetation type being much less important, though still entering the second best model (Table 1; Appendix C). The curvilinear decline appears largely to be a consequence of stable densities up to $\sim 100 \mathrm{~m}$ elevation and declines thereafter. For the alien species, both vegetation type and altitude entered the best model (Table 1; Appendix D), with a linear decline in density with increasing elevation (Fig. 1b). In both cases, the GWR models had much higher $\mathrm{AIC}_{\mathrm{c}}$ weights 
TABLE 1. Model selection summary for the best models based on Akaike Information Criterion weights $\left(w_{i}\right)$ for the density and species richness of indigenous and alien springtails (Collembola) on Macquarie Island, Tasmania, Australia.

\begin{tabular}{|c|c|c|c|c|c|c|c|c|c|}
\hline \multirow[b]{2}{*}{ Model (GWR) } & \multirow[b]{2}{*}{ Variables } & \multirow[b]{2}{*}{ nVars } & \multirow[b]{2}{*}{$R^{2}$} & \multirow[b]{2}{*}{$\mathrm{AIC}_{\mathrm{c}}$} & \multirow[b]{2}{*}{$\Delta \mathrm{AIC}_{\mathrm{c}}$} & \multirow[b]{2}{*}{$w_{i}$} & \multicolumn{3}{|c|}{ Nonstationarity evidence } \\
\hline & & & & & & & $F$ & $\mathrm{df}$ & $P$ \\
\hline \multicolumn{10}{|c|}{ Indigenous density } \\
\hline 1 & $(-) \mathrm{ALT}^{2}$ & 8.5 & 0.75 & 47.69 & 0 & 0.78 & 7.8 & 8,34 & $<0.0001$ \\
\hline 2 & $(-) \mathrm{ALT}^{2}, \mathrm{VEG}$ & 8.8 & 0.74 & 50.84 & 3.15 & 0.16 & 5.4 & 5,36 & 0.0001 \\
\hline \multicolumn{10}{|l|}{ Alien density } \\
\hline 1 & $(-) A L T$, VEG & 8.8 & 0.72 & 125.28 & 0 & 0.72 & 4.8 & 4,37 & 0.003 \\
\hline 2 & $(-) \mathrm{ALT}$ & 6.12 & 0.63 & 128.85 & 3.57 & 0.12 & 4.35 & 4,38 & 0.005 \\
\hline \multicolumn{10}{|c|}{ Indigenous richness } \\
\hline 1 & $(-) \mathrm{ALT}, \mathrm{VEG}$ & 5.2 & 0.38 & 194.58 & 0 & 0.53 & 4.7 & 2,39 & 0.015 \\
\hline 2 & $(-) \mathrm{ALT}^{2}, \mathrm{VEG}$ & 5.1 & 0.38 & 196.29 & 1.71 & 0.22 & 4.3 & 2,39 & 0.021 \\
\hline \multicolumn{10}{|l|}{ Alien richness } \\
\hline 1 & $(-) \mathrm{ALT}^{2}$ & 7.2 & 0.52 & 128.58 & 0 & 0.66 & 4.8 & 5,37 & $<0.002$ \\
\hline 2 & (-)ALT, VEG & 6.8 & 0.48 & 131.16 & 2.58 & 0.18 & 4.2 & 4,37 & $<0.007$ \\
\hline
\end{tabular}

Notes: The predictor variables included in the models were: vegetation (VEG), altitude (ALT), and altitude squared (ALT ${ }^{2}$ ). GWR is geographically weighted regression; nVars indicates the effective number of variables used in the models. For the 10 best models, see Appendices C-F. Significant $P$ values are evidence of nonstationarity.

than any of the other models, indicating spatial nonstationarity in the data and the best model explained $>70 \%$ of the variation in the data (Appendices $\mathrm{C}$ and D). Monte-Carlo $F$ tests showed that GWR models were a significant improvement on corresponding OLS models for both indigenous and alien species densities, but the improvement was much more significant for indigenous species density, indicating these data had more nonstationarity compared with those for alien species density (Table 1).

Indigenous species richness was most strongly related to altitude and vegetation with both terms present in the two best models (Table 1; Appendix E). The decline in indigenous richness with altitude was best described by a linear relationship (Fig. 1c). By contrast, the best model for the alien assemblages contained only the quadratic altitude term, suggesting that the decline with altitude was weakly curvilinear in nature (Fig. 1d). Although not as important as for indigenous species richness, the vegetation term was present in the second best alien richness model (Table 1; Appendix F). GWR models had higher $\mathrm{AIC}_{\mathrm{c}}$ weights than OLS and SAR models, with the best models explaining over $50 \%$ and $60 \%$ of the variation for indigenous and alien species richness, respectively (Appendices $\mathrm{E}$ and $\mathrm{F}$ ). By contrast with the density models, the improvement of GWRs on the OLS models was much better for alien richness (Table 1), suggesting that there is more nonstationarity in these data compared with indigenous species richness.

When the density and species richness variables were added to the models at this scale, the two best models for variation in alien species richness were single term GWR models, the first with a negative squared altitude term (AIC $\mathrm{c}_{\mathrm{c}}$ weight $0.19, R^{2}=0.52$ ) and the second indicating a positive relationship with the density of indigenous species $\left(\mathrm{AIC}_{\mathrm{c}}\right.$ weight $=0.16 ; R^{2}=0.40 ;$ Table 2 ; Appendix G). Thus, where density of the indigenous species was high, alien species richness was high. By contrast, vegetation type (and altitude) continued to be important in the two best models for the density of the alien species, although the entry of the DIS $\times$ vegetation type interaction term in the best model indicated that while in some vegetation types the relationship between the densities of alien and indigenous species was positive in others it was negative (Table 3, Fig. 1e, f). Here, the two best models had $\mathrm{AIC}_{\mathrm{c}}$ weights differing by only 0.1 , with the second best one excluding the interaction effect, and together they accounted for $>70 \%$ of the variation in alien species density (see also Appendix H).

\section{Interaction neighborhood scale}

At the smaller scale, represented by samples, the best models for alien species richness included a negative relationship with altitude, positive relationships with indigenous species richness, and an interaction term indicating differences in relationships between alien species richness and the density of indigenous species in different habitat types (Table 2; Appendix I). Typically the relationship between alien species richness and the density of indigenous species was positive, except in Colobanthus-dominated habitats where it was negative (Table 3). For the density of alien species the best models consistently included a curvilinear decline with altitude, a negative relationship with indigenous richness, and positive covariation with the DIS $\times$ vegetation interaction term (Table 2; Appendix J). Here the negative relationships between the density of alien species and the density of indigenous species were found in the Colobanthus-dominated and Stilbocarpa-dominated habitat types (Table 3). Importantly, at this interaction neighborhood scale the relationships among the alien and indigenous species in terms of both richness and density were more complicated than at the metacommunity scale. Moreover, at the local 
TABLE 2. Summary of the two best models for density (log-transformed) and richness of alien and indigenous species at the site (metacommunity) and sample (interaction neighborhood) scales.

\begin{tabular}{|c|c|c|c|c|c|c|c|}
\hline \multirow{2}{*}{$\begin{array}{l}\text { Response } \\
\text { variable }\end{array}$} & \multirow{2}{*}{$\begin{array}{l}\text { Type of two } \\
\text { best models }\end{array}$} & \multirow[b]{2}{*}{ Predictors from two best models } & \multirow[b]{2}{*}{ Mean $R^{2}$} & \multirow{2}{*}{$\begin{array}{l}\text { Sum } \mathrm{AIC}_{\mathrm{c}} \\
\text { weights }\end{array}$} & \multicolumn{3}{|c|}{ Nonstationarity evidence } \\
\hline & & & & & $F$ & df & $P$ \\
\hline ASR (Site) & GWR/GWR $†$ & $(-) \mathrm{ALT}^{2},(+) \mathrm{DIS}$ & 0.46 & 0.34 & 4.8 & 5,37 & $<0.002$ \\
\hline ASR (Sample) & GWR/GWR & $\begin{array}{l}(-) \mathrm{ALT}_{,}(+) \mathrm{ISR},(+) \mathrm{ISR}^{2}, \\
(+) \mathrm{DIS} \times \mathrm{VEG}\end{array}$ & 0.47 & 0.52 & 12.9 & 14,332 & $<0.00001$ \\
\hline DAS (Site) & GWR/GWR & VEG $,(-) \mathrm{ALT},(+) \mathrm{DIS} \times \mathrm{VEG}$ & 0.73 & 0.71 & 4.9 & 6,34 & $<0.002$ \\
\hline DAS (Sample) & GWR/GWR & $\begin{array}{l}\text { VEG, }(+) \mathrm{ALT}_{,}(-) \mathrm{ALT}^{2},(-) \mathrm{ISR}^{2}, \\
(+) \mathrm{DIS} \times \mathrm{VEG}\end{array}$ & 0.57 & 0.84 & 6.4 & 35,312 & $<0.00001$ \\
\hline \multicolumn{8}{|c|}{ Reciprocal analyses } \\
\hline ISR (Site) & $\mathrm{GWR} \uparrow / \mathrm{OLS}$ & $\begin{array}{l}(-) \mathrm{ALT}_{,},(-) \mathrm{HD}^{2},(+) \mathrm{HD} \times \mathrm{VEG} \\
(+) \mathrm{OD},(-) \mathrm{OD}^{2}\end{array}$ & 0.47 & 0.52 & 3.06 & 1,37 & $<0.09$ \\
\hline ISR (Sample) & $\mathrm{SAR} / \mathrm{SAR}$ & $\begin{array}{l}\text { VEG, }(-) \mathrm{ALT},(+) \mathrm{HD},(-) \mathrm{HD}^{2}, \\
(+) \mathrm{HD} \times \mathrm{VEG},(+) \mathrm{OD}, \\
(-) \mathrm{OD} \times \mathrm{VEG},(-) \mathrm{ASR},(+) \mathrm{ASR}^{2}\end{array}$ & 0.45 & 0.71 & & & \\
\hline DIS (Site) & GWR/GWR & VEG, $(-) \mathrm{ALT}^{2}$ & 0.75 & 0.85 & 6.5 & 7,34 & $<0.0001$ \\
\hline DIS (Sample) & GWR/GWR & $\mathrm{VEG},(-) \mathrm{ALT}^{2},(+) \mathrm{ASR}$ & 0.59 & 0.97 & 11.5 & 16,330 & $<0.00001$ \\
\hline
\end{tabular}

Notes: For the 10 best models see Appendices G-J. Predictor variables are vegetation (VEG), altitude (ALT), density of indigenous species (DIS), indigenous species richness (ISR), density of all alien species (DAS), alien species richness (ASR), hypogastrurid alien density (HD), other alien density (OD). Statistics in the last three columns represent the mean evidence of the two best models for nonstationarity, indicated by values of $P<0.05$. No statistics are given for ISR (sample) because GWR models were not the two best models; hence there was no nonstationarity.

$\dagger$ Even though there was little evidence for nonstationarity $\left(F_{1,41}=3.2, P<0.08\right)$ in the second-best GWR model, it was used due to higher $\mathrm{AIC}_{\mathrm{c}}$ weights.

metacommunity scale the effect of environmental favorability, as represented by altitude, tended to dominate, with any effects of indigenous diversity tending to be positive. By contrast at the interaction neighborhood scale the direction of interactions tended to be more negative.

\section{Reciprocal influences}

Discerning the likely causality of interactions is problematic in correlational analyses. Indigenous species might be resisting the colonization of a neighborhood or metacommunity, or the alien species might have become invasive and might be responsible for a decline in the indigenous species (to local extirpation if a species is not present). To investigate how these alternatives might be playing out, recognizing that both may be occurring sequentially or simultaneously in different areas, we reran our full models at both scales, but now with indigenous species richness or the density of the indigenous species as the dependent variables (Table 2; Appendices $\mathrm{K}-\mathrm{N}$ ). However, we split the alien species into two groups and examined the effects of the density of these two groups separately. The first group includes only the hypogastrurid species (Hypogastrura viatica, $H$. purpurescens, and Ceratophysella denticulata). The members of this family are known to dominate areas where

TABLE 3. Direction of significant covariation, $R^{2}$, and significance from models between alien or indigenous species density and the density and richness of alien and indigenous species in nine vegetation types at site (metacommunity) and samples (interaction neighborhood) scales.

\begin{tabular}{|c|c|c|c|c|c|c|c|c|}
\hline \multirow{2}{*}{$\begin{array}{c}\text { Response } \\
\text { variable }\end{array}$} & \multicolumn{2}{|c|}{ ASR } & \multicolumn{2}{|c|}{ DAS } & \multicolumn{4}{|c|}{ ISR } \\
\hline & Site scale & Sample scale & Site scale & Sample scale & Site scale & Sample scale & Site scale & Sample scale \\
\hline Interaction term & $\mathrm{DIS} \times \mathrm{VEG}$ & $\mathrm{DIS} \times \mathrm{VEG}$ & DIS $\times$ VEG & $\mathrm{DIS} \times \mathrm{VEG}$ & $\mathrm{HD} \times \mathrm{VEG}$ & $\mathrm{HD} \times \mathrm{VEG}$ & $\mathrm{OD} \times \mathrm{VEG}$ & $\mathrm{OD} \times \mathrm{VEG}$ \\
\hline Acaena & $\mathrm{N} / \mathrm{A}$ & $(+) 0.61 * * *$ & & $(+) 0.6 * * *$ & $(-) 0.92 *$ & $(-) 0.32 * * *$ & $\mathrm{~N} / \mathrm{A}$ & $(+) 0.29 * *$ \\
\hline Azorella & $\mathrm{N} / \mathrm{A}$ & $(+) 0.18^{*}$ & & $(+) 0.18^{*}$ & & & $\mathrm{~N} / \mathrm{A}$ & \\
\hline Colobanthus & $\mathrm{N} / \mathrm{A}$ & $(-) 0.57 * * *$ & $(-) 0.94^{*}$ & $(-) 0.52 * * *$ & $(-) 0.95^{*}$ & $(-) 0.52 * * *$ & $\mathrm{~N} / \mathrm{A}$ & $(+) 0.57 * * *$ \\
\hline Mire & $\mathrm{N} / \mathrm{A}$ & & $(+) 0.74 *$ & $(+) 0.52 * * *$ & & $(-) 0.28 * * *$ & $\mathrm{~N} / \mathrm{A}$ & \\
\hline Pleurophyllum & $\mathrm{N} / \mathrm{A}$ & & & & $(+) 0.97 * *$ & & $\mathrm{~N} / \mathrm{A}$ & $(+) 0.12 *$ \\
\hline Polystichum & $\mathrm{N} / \mathrm{A}$ & & & & & & $\mathrm{N} / \mathrm{A}$ & \\
\hline Short grass & $\mathrm{N} / \mathrm{A}$ & $(+) 0.15^{*}$ & & & & & $\mathrm{~N} / \mathrm{A}$ & \\
\hline Stilbocarpa & $\mathrm{N} / \mathrm{A}$ & & & $(-) 0.58 * * *$ & $(+) 0.72 *$ & & $\mathrm{~N} / \mathrm{A}$ & \\
\hline Tall tussock & $\mathrm{N} / \mathrm{A}$ & & & $(+) 0.54 * * *$ & & & $\mathrm{~N} / \mathrm{A}$ & \\
\hline
\end{tabular}

Notes: All densities were log-transformed. As predictor variables, alien species densities were split by taxa into hypogastrurids (HD) and other species (OD), and alien species richness (ASR), indigenous species richness (ISR), the density of alien species (DAS), and the density of indigenous species (DIS). The 10 best overall models in each case are provided in Appendices G, H, I, J, $\mathrm{M}$, and $\mathrm{N}$. Only significant $(P<0.05)$ interactions are included. That is, blank cells indicate that the interactions were present, but not significant. For ASR at the site scale, N/A (not applicable) indicates that there was no DIS $\times$ VEG interaction term in the two best models. For ISR at the site scale, N/A indicates that there was no OD $\times$ VEG interaction term in the two best models.

* $P<0.05 ; * * P<0.01 ; * * * P<0.001$. 
they are present as alien species and to have substantial impacts on indigenous species, possibly leading to their exclusion (Convey et al. 1999, Greenslade 2002). By contrast, the species in the other group (Desoria sp., Lepidocyrtus sp.) have not been shown to have such effects.

These analyses indicated substantial complexity in the relationships among the indigenous species and the aliens. At the metacommunity level, the density of indigenous species largely declined with altitude and was affected by vegetation type, with no effect of the density of the hypogastrurid or other species. This pattern was repeated at the interaction neighborhood scale, though with some positive covariation with alien species richness (Table 2; Appendices $\mathrm{K}$ and $\mathrm{L}$ ). However, in both cases the models including the altitude or altitude and vegetation predictors only, far outperformed the other models $\left(\mathrm{AIC}_{\mathrm{c}}\right.$ weight $=0.70$ and 0.96 , for the metacommunity and interaction neighborhood scales, respectively). By contrast, at the metacommunity scale, hypogastrurid density had both positive and negative relationships with indigenous species richness depending on vegetation type, whereas at the interaction neighborhood scale the relationships were negative in all vegetation types (Table 3; see also Appendices $M$ and $\mathrm{N})$. The interaction of indigenous species richness with the density of the other alien group was either generally curvilinear (metacommunity scale) or showed positive relationships within the vegetation types where the relationships were significant (interaction neighborhood) (Tables 2 and 3).

\section{DisCUSSION}

At the larger, local metacommunity scale it is clear that both indigenous and alien springtail diversity respond strongly to declining environmental favorability, represented here by altitude. At Macquarie Island temperatures decline rapidly with elevation, with strong effects on both the vegetation (Selkirk et al. 1990) and on other invertebrate groups (Davies and Melbourne 1999, Greenslade 2006). The decline in diversity with elevation and the variation in both density and richness among vegetation types are typical of springtails elsewhere in the region (Convey et al. 1999, Gabriel et al. 2001). Positive relationships between diversity and measures of environmental favorability have also been found for springtails elsewhere (Ulrich and Fiera 2009). That these relationships vary among the indigenous and alien species has also been found previously in the subantarctic, with the former tending to show stronger relationships with the habitats than the latter (Gabriel et al. 2001).

Given the generally similar responses of springtails across a range of regions to environmental favorability, and to high productivity lowland areas, particularly in the subantarctic (Gabriel et al. 2001), it is unsurprising that at the metacommunity scale the relationships among the alien and indigenous species richness and density were largely positive. In essence, it appears that these positive relationships are a consequence of similar responses by the species to differences among the local metacommunities in their mean environmental conditions, as both theoretical and modeling work has shown should be the case (Shea and Chesson 2002, Melbourne et al. 2007). For example, tall tussock grassland (mean altitude $52 \mathrm{~m}$ ) supports 18 species at a mean density of 194330 individuals $/ \mathrm{m}^{2}$, whereas in the high elevation, Azorella-dominated sites (mean altitude $261 \mathrm{~m}$ ) total species richness is 13 with mean total density reaching only 3351 individuals $/ \mathrm{m}^{2}$. Although differences in heterogeneity among metacommunities may also have played a role in establishing the positive relationship (Davies et al. 2005), our sampling across the island was not sufficiently extensive for us to be confident that betadiversity (or heterogeneity within sites) also plays a role in establishing the positive relationship among indigenous and alien diversity at this scale. Nonetheless, the results show that for springtails at this scale, no grounds exist for rejecting the "rich get richer" hypothesis (Stohlgren et al. 1999), in keeping with the outcomes of studies of a wide range of other groups (Herben et al. 2004, Chown et al. 2005, Evans et al. 2005, Borges et al. 2006, Fridley et al. 2007, Stohlgren et al. 2008).

Although theory suggests that competition should result in a negative relationship among alien and indigenous species richness at the interaction neighborhood scale (e.g., Shea and Chesson 2002, Davies et al. 2005, Melbourne et al. 2007), matters can also be more complicated when both richness and abundance are considered (e.g., Diez et al. 2008). Here we found that at the smallest scale, alien richness tended to vary positively with indigenous species richness and with indigenous species density in most vegetation types, but in some cases the relationship among alien species richness and/or density, and the density of indigenous species was negative. Although some temporal variation may have been involved in these changing relationships, we consider the influence minimal given the rather limited seasonal variation over the summer on Macquarie Island (Pendlebury and Barnes-Keoghan 2007), and that seasonal effects are typically not pronounced in the region's invertebrates over such time scales (see Convey 1996, Barendse and Chown 2001).

Further exploration of the relationships among the diversity of the alien and indigenous groups, by means of the reciprocal analyses, provided additional insight into possible mechanisms underlying the increasing complexity of interactions at the smallest spatial scale. Although the initial analyses revealed some negative interactions among the density of indigenous and alien species at the sample scale (specifically in Colobanthus and Stilbocarpa), when the reciprocal analyses were undertaken, dividing the alien species into hypogastrurids and other taxa, the interaction between indigenous and alien density was not found. These differences may be a consequence of the depth stratification of spring- 
tails that is commonly found in the soil (Hopkin 1997). Some groups, such as the hypogastrurids and the indigenous Lepidobrya mawsoni and Cryptopygus antarcticus are surface and litter dwellers, while others, such as Tullbergia bisetosa occur in deeper layers of the soil (Janion et al. 2010). Thus, while negative interactions among species inhabiting the same soil layers may be taking place, other explanations for negative covariation cannot be excluded. Only more detailed investigations, involving experimental manipulations, will uncover the causal nature of the interactions among the individual species. Nonetheless, the reciprocal analyses did reveal a negative relationship between indigenous species richness overall and hypogastrurid density in several vegetation types, and a positive relationship between indigenous species richness and the density of the other alien springtail taxa. This outcome suggests that although the impacts of the hypogastrurids on the overall density of the indigenous species might not be significant, specific impacts occur which reduce species richness, even when taking all of the other environmental factors into account. Owing to the depth distributions of the species concerned, only more detailed work, perhaps including manipulative experiments will reveal the causal nature of these interactions. Here, it should be kept in mind that the high densities of the hypogastrurids may be having more than a straightforward direct effect on species sharing the same soil depth in these habitats. Complex interactions among components of the soil fauna and between above- and belowground components of the same systems have been reported previously (e.g., Wardle et al. 2004). Whatever the ultimate nature of the interactions, that they differ among the hypogastrurids and other alien springtails suggests that species identity is an important factor for understanding the impacts of these invasive species, as has been found for other taxa (e.g., Richardson and Pyšek 2006, Blackburn et al. 2009, Orrock and Witter 2010).

Overall, our results for springtails support the idea that the interactions among indigenous and alien species change substantially with spatial scale, and largely in a manner consistent both with theory (Byers and Noonburg 2003, Melbourne et al. 2007) and with what has been found for other taxa (Herben et al. 2004, Davies et al. 2005, Fridley et al. 2007). However, they also suggest that these interactions may not only be affected by scale and the differing productivity among habitats, but also, and especially at the finest scales, by the identity of the species concerned and by their abundances. Given the typical complexity of interactions at the local scale (Lawton 1999) such a finding is not unsurprising. Perhaps more importantly, it appears that from the habitat scale upward, generalizations can be made readily, and in this case that environmental favorability tends to have the same positive effects on both indigenous and alien species diversity. What is less clear is whether this relationship, which also extends to much broader scales (e.g., Sax and Gaines 2003, 2008), will remain with ongoing introductions of alien species, and whether the small-scale negative relationships among indigenous and alien species will eventually extend to broader spatial scales, especially in lower productivity or more disturbed environments (Davies et al. 2007). Recent (post-2002) and substantial changes in the Macquarie Island environment, owing to an increase in invasive rabbit abundance, which has led to considerable disturbance and loss of indigenous vegetation (Bergstrom et al. 2009), provide a useful experimental setting for addressing this question.

\section{ACKNOWLEDGMENTS}

We thank Christine Hänel for technical assistance at Macquarie Island, Justine Shaw for discussion, Melodie McGeoch and two anonymous reviewers for comments on a previous version of the manuscript, and the Tasmanian Parks and Wildlife Service for permission to conduct research on Macquarie Island. This work was jointly funded by the Australian Antarctic Division and the Centre for Invasion Biology.

\section{Literature Cited}

Auclerc, A., J. F. Ponge, S. Barot, and F. Dubs. 2009. Experimental assessment of habitat preference and dispersal ability of soil springtails. Soil Biology and Biochemistry 41:1596-1604.

Banerjee, S., B. P. Carlin, and A. E. Gelfand. 2004. Hierarchical modelling and analysis for spatial data. Chapman and Hall/ CRC, Boca Raton, Florida, USA.

Barendse, J., and S. L. Chown. 2001. Abundance and seasonality of mid-altitude fellfield arthropods from Marion Island. Polar Biology 24:72-82.

Beale, C. M., J. J. Lennon, D. A. Elston, M. J. Brewer, and J. M. Yearsley. 2007. Red herrings remain in geographical ecology: a reply to Hawkins et al. (2007). Ecography 30:845847.

Beale, C. M., J. J. Lennon, J. M. Yearsley, M. J. Brewer, and D. A. Elston. 2010. Regression analysis of spatial data. Ecology Letters 13:246-264.

Begueria, S., and Y. Pueyo. 2009. A comparison of simultaneous autoregressive and generalized least squares models for dealing with spatial autocorrelation. Global Ecology and Biogeography 18:273-279.

Bergstrom, D. M., A. Lucieer, K. Kiefer, J. Wasley, L. Belbin, T. K. Pedersen, and S. L. Chown. 2009. Indirect effects of invasive species removal devastate World Heritage Island. Journal of Applied Ecology 46:73-81.

Bini, L. M., et al. 2009. Coefficient shifts in geographical ecology: an empirical evaluation of spatial and non-spatial regression. Ecography 32:193-204.

Blackburn, T. M., P. Cassey, R. P. Duncan, K. L. Evans, and K. J. Gaston. 2004. Avian extinction and mammalian introductions on oceanic islands. Science 305:1955-1958.

Blackburn, T. M., J. L. Lockwood, and P. Cassey. 2009. Avian invasions. The ecology and evolution of exotic birds. Oxford University Press, Oxford, UK.

Borges, P. A. V., J. M. Lobo, E. B. de Azevedo, C. S. Gaspar, C. Melo, and L. V. Nunes. 2006. Invasibility and species richness of island endemic arthropods: a general model of endemic vs. exotic species. Journal of Biogeography 33:169187.

Burnham, K. P., and D. R. Anderson. 2002. Model selection and multimodel inference: a practical information-theoretic approach. Springer, New York, New York, USA. 
Byers, J. E., and E. G. Noonburg. 2003. Scale dependent effects of biotic resistance to biological invasion. Ecology 84:14281433.

Chesson, P. L., and R. P. Warner. 1981. Environmental variability promotes coexistence in lottery competitive systems. American Naturalist 117:923-943.

Chown, S. L., B. Hull, and K. J. Gaston. 2005. Human impacts, energy availability and invasion across Southern Ocean Islands. Global Ecology and Biogeography 14:521-528.

Colwell, R. K. 2006. EstimateS: statistical estimation of species richness and shared species from samples. Version 8. 〈purl.oclc.org/estimates〉

Convey, P. 1996. The influence of environmental characteristics on life history attributes of Antarctic terrestrial biota. Biological Reviews 71:191-225.

Convey, P., P. Greenslade, R. J. Arnold, and W. Block. 1999. Collembola of sub-Antarctic South Georgia. Polar Biology 22:1-6.

Davies, K. F., P. Chesson, S. Harrison, B. D. Inouye, B. A. Melbourne, and K. J. Rice. 2005. Spatial heterogeneity explains the scale dependence of the native-exotic diversity relationship. Ecology 86:1602-1610.

Davies, K. F., S. Harrison, H. D. Safford, and J. H. Viers. 2007. Productivity alters the scale dependence of the diversityinvasibility relationship. Ecology 88:1940-1947.

Davies, K. F., and B. A. Melbourne. 1999. Statistical models of invertebrate distribution on Macquarie Island: a tool to assess climate change and local human impacts. Polar Biology 21:240-250.

Deharveng, L. 1981. Collemboles des îles subantarctiques de l'Ocean Indien. Comité National Française des Recherches Antarctiques 48:33-108.

Diez, J. M., J. J. Sullivan, P. E. Hulme, G. Edwards, and R. P. Duncan. 2008. Darwin's naturalization conundrum: dissecting taxonomic patterns of species invasions. Ecology Letters 11:674-681.

Evans, K. L., P. H. Warren, and K. J. Gaston. 2005. Does energy availability influence classical patterns of spatial variation in exotic species richness? Global Ecology and Biogeography 14:57-65.

Foody, G. M. 2004. Spatial nonstationarity and scaledependency in the relationship between species richness and environmental determinants for the sub-Saharan endemic avifauna. Global Ecology and Biogeography 13:315-320.

Foody, G. M. 2005. Clarifications on local and global data analysis. Global Ecology and Biogeography 14:99-100.

Fotheringham, A. S., C. Brunsdon, and M. Charlton. 2002. Geographically weighted regression: the analysis of spatially varying relationships. Wiley, Chichester, UK.

Fridley, J. D., R. L. Brown, and J. F. Brundu. 2004. Null models of exotic invasion and scale dependent patterns of native and exotic species richness. Ecology 85:3215-3222.

Fridley, J. D., J. J. Stachowicz, S. Naeem, D. F. Sax, E. W. Seabloom, M. D. Smith, T. J. Stohlgren, D. Tilman, and B. Von Holle. 2007. The invasion paradox: reconciling pattern and process in species invasions. Ecology 88:3-17.

Gabriel, A. G. A., S. L. Chown, J. Barendse, D. J. Marshall, R. D. Mercer, P. J. A. Pugh, and V. R. Smith. 2001. Biological invasions of Southern Ocean islands: the Collembola of Marion Island as a test of generalities. Ecography 24:421-430.

Gaston, K. J., T. M. Blackburn, and R. D. Gregory. 1999. Does variation in census area confound density comparisons? Journal of Applied Ecology 36:191-204.

Greenslade, P. 2002. Assessing the risk of exotic Collembola invading subantarctic islands: prioritising quarantine management. Pedobiologia 46:338-344.

Greenslade, P. 2006. The invertebrates of Macquarie Island. Australian Antarctic Division, Kingston, Tasmania, Australia.
Herben, T., B. Mandak, K. Bimova, and Z. Munzbergova. 2004. Invasibility and species richness of a community: a neutral model and a survey of published data. Ecology 85:3223-3233.

Hopkin, S. P. 1997. Biology of the springtails. Oxford University Press, Oxford, UK.

Hulme, P. E. 2009. Trade, transport and trouble: managing invasive species pathways in an era of globalization. Journal of Applied Ecology 46:10-18.

Janion, C., H. P. Leinaas, J. S. Terblanche, and S. L. Chown. 2010. Trait means and reaction norms: the consequences of climate change/invasion interactions at the organism level. Evolutionary Ecology 24:1365-1380.

Jetz, W., C. Rahbek, and J. W. Lichstein. 2005. Local and global approaches to spatial data analysis in ecology. Global Ecology and Biogeography 14:97-98.

Kumar, S., T. J. Stohlgren, and G. W. Chong. 2006. Spatial heterogeneity influences native and nonnative plant species richness. Ecology 87:3186-3199.

Lawton, J. H. 1999. Are there general laws in ecology? Oikos 84:177-192.

Levine, J. M., P. B. Adler, and S. G. Yelenik. 2004. A metaanalysis of biotic resistance to exotic plant invasions. Ecology Letters 7:975-989.

Loffler, E. 1983. Macquarie Island-eine vom Wind gepragte Naturlandschaft in der Sub-Antarktis. Polarforschung 53:59-74.

Mack, R. N., D. Simberloff, W. M. Lonsdale, H. Evans, M. Clout, and F. A. Bazzaz. 2000. Biotic invasions: causes, epidemiology, global consequences, and control. Ecological Applications 10:689-710.

Magurran, A. E. 2004. Measuring biological diversity. Blackwell Science, Oxford, UK.

McGeoch, M. A., S. H. M. Butchart, D. Spear, E. Marais, E. J. Kleynhans, A. Symes, J. Chanson, and M. Hoffmann. 2010. Global indicators of biological invasion: species numbers, biodiversity impact and policy responses. Diversity and Distributions 16:95-108.

Melbourne, B. A., et al. 2007. Invasion in a heterogeneous world: resistance, coexistence or hostile takeover? Ecology Letters 10:77-94.

O'Dowd, D. J., P. T. Green, and P. S. Lake. 2003. Invasional 'meltdown' on an oceanic island. Ecology Letters 6:812-817.

Orrock, J. L., M. L. Baskett, and R. D. Holt. 2010. Spatial coincidence of plant competition and consumer foraging mediate plant coexistence and drive the invasion ratchet. Proceedings of the Royal Society B 277:3307-3315.

Orrock, J. L., and M. S. Witter. 2010. Multiple drivers of apparent competition reduce re-establishment of a native plant in invaded habitats. Oikos 119:101-108.

Pendlebury, S. F., and I. P. Barnes-Keoghan. 2007. Climate and climate change in the sub-Antarctic. Papers and Proceedings of the Royal Society of Tasmania 141:67-82.

Peterson, H., and M. O. Luxton. 1982. A comparative analysis of soil fauna populations and their role in decomposition processes. Oikos 39:288-388.

Ponge, J. F., T. Tully, and A. Gins. 2008. Short-term responses of two Collembolan communities after abrupt environmental perturbation: a field experimental approach. Pedobiologia 52:19-28.

Rangel, T. F. L. V. B., J. A. F. Diniz-Filho, and L. M. Bini. 2006. Towards an integrated computational tool for spatial analyses in macroecology and biogeography. Global Ecology and Biogeography 15:321-327.

Richardson, D. M., and P. Pyšek. 2006. Plant invasions: merging the concepts of species invasiveness and community invasibility. Progress in Physical Geography 30:409-431.

Sax, D. F., and S. D. Gaines. 2003. Species diversity: from global decreases to local increases. Trends in Ecology and Evolution 18:561-566. 
Sax, D. F., and S. D. Gaines. 2008. Species invasions and extinction: the future of native biodiversity on islands. Proceedings of the National Academy of Sciences USA 105:11490-11497.

Selkirk, P. M., and D. A. Adamson. 1995. Map of structural vegetation types and drainage on subantarctic Macquarie Island. Macquarie University, available from Australian Antarctic Division Data Centre, Kingston, Tasmania, Australia.

Selkirk, P. M., R. D. Seppelt, and D. R. Selkirk. 1990. Subantarctic Macquarie Island: environment and biology. Cambridge University Press, Cambridge, UK.

Seppelt, R. 2004. The moss flora of Macquarie Island. Australian Antarctic Division, Kingston, Tasmania, Australia.

Shea, K., and P. Chesson. 2002. Community ecology theory as a framework for biological invasions. Trends in Ecology and Evolution 17:170-176.

Stachowicz, J. J., H. Fried, R. W. Osman, and R. B. Whitlatch. 2002. Biodiversity, invasion resistance, and marine ecosystem function: reconciling pattern and process. Ecology 83:25752590 .

Starzomski, B. M., R. L. Parker, and D. S. Srivastava. 2008. On the relationship between regional and local species richness: a test of saturation theory. Ecology 89:1921-1930.
Stohlgren, T. J., D. T. Barnett, C. S. Jarnevich, C. Flather, and J. Kartesz. 2008. The myth of plant species saturation. Ecology Letters 11:313-322.

Stohlgren, T. J., D. Binkley, G. W. Chong, M. A. Kalkhan, L. D. Schell, K. A. Bull, Y. Otsuki, G. Newman, M. Bashkin, and Y. Son. 1999. Exotic plant species invade hot spots of native plant diversity. Ecological Monographs 69:25-46.

Tweedie, C. E., and D. M. Bergstrom. 2000. A climate change scenario for surface air temperature at sub-Antarctic Macquarie Island. Pages 272-281 in W. Davison, C. H. Williams, and P. Broady, editors. Antarctic ecosystems: models for wider understanding. New Zealand Natural Sciences, Christchurch. New Zealand.

Ulrich, W., and C. Fiera. 2009. Environmental correlates of species richness of European springtails (Hexapoda: Collembola). Acta Oecologica 35:45-52.

van Kleunen, M., E. Weber, and M. Fischer. 2010. A metaanalysis of trait differences between invasive and noninvasive plant species. Ecology Letters 13:235-245.

van Straalen, N. M. 1994. Adaptive significance of temperature responses in Collembola. Acta Zoologica Fennica 195:135142.

Wardle, D. A., R. D. Bardgett, J. N. Klironomos, H. Setala, W. H. van der Putten, and D. H. Wall. 2004. Ecological linkages between aboveground and belowground biota. Science 304:1629-1633.

\section{APPENDIX A}

Rarefaction curve for nine vegetation types on Macquarie Island standardized by sample effort of springtails (Ecological Archives E092-123-A1).

\section{APPENDIX B}

Mean density of each of the springtail species in each vegetation type sampled on Macquarie Island (Ecological Archives E092123-A2).

\section{APPENDIX C}

Model selection summary for the density of indigenous species at the site scale (metacommunity), with predictor variables of vegetation (VEG), altitude (ALT), and altitude squared (ALT ${ }^{2}$ ) (Ecological Archives E092-123-A3).

\section{APPENDIX D}

Model selection summary for the density of alien species at the site scale (metacommunity), with predictor variables of VEG, ALT, and $\mathrm{ALT}^{2}$ (Ecological Archives E092-123-A4).

\section{APPENDIX E}

Model selection summary for indigenous species richness at the site scale (metacommunity), with predictor variables of VEG, ALT, and $\mathrm{ALT}^{2}$ (Ecological Archives E092-123-A5)

\section{APPENDIX F}

Model selection summary for alien species richness at the site scale (metacommunity), with predictor variables of VEG, ALT, and $\mathrm{ALT}^{2}$ (Ecological Archives E092-123-A6).

\section{APPENDIX G}

Model selection summary for alien richness at the site scale (metacommunity), with predictor variables of VEG, ALT, ALT ${ }^{2}$, density indigenous species (DIS), DIS ${ }^{2}$, DIS $\times$ VEG, indigenous species richness (ISR), and ISR ${ }^{2}$ (Ecological Archives E092-123A7). 


\section{APPENDIX H}

Model selection summary for the density of alien species at the site scale (metacommunity), with predictor variables VEG, ALT, $\mathrm{ALT}^{2}$, DIS, DIS ${ }^{2}, \mathrm{DIS} \times$ VEG, ISR, and $\mathrm{ISR}^{2}$ (Ecological Archives E092-123-A8).

\section{APPENDIX I}

Model selection summary for alien richness at the sample scale (interaction neighborhood), with predictor variables VEG, ALT, $\mathrm{ALT}^{2}$, DIS, DIS ${ }^{2}$, DIS $\times$ VEG, ISR, and ISR ${ }^{2}$ (Ecological Archives E092-123-A9).

\section{APPENDIX J}

Model selection summary for density of alien species at the sample scale (interaction neighborhood), with predictor variables VEG, ALT, ALT ${ }^{2}$, DIS, DIS ${ }^{2}$, DIS $\times$ VEG, ISR, and ISR ${ }^{2}$ (Ecological Archives E092-123-A10).

\section{APPENDIX K}

Model selection summary for density of indigenous species at the site scale (metacommunity), with predictor variables VEG, $\mathrm{ALT}, \mathrm{ALT}^{2}$, alien species richness (ASR), $\mathrm{ASR}^{2}$, hypogastrurid density (HD), $\mathrm{HD}^{2}, \mathrm{HD} \times \mathrm{VEG}$, other alien density (OD), OD ${ }^{2}$, and OD $\times$ VEG (Ecological Archives E092-123-A11).

\section{APPENDIX L}

Model selection summary for density of indigenous species at the sample scale (interaction neighborhood), with predictor variables VEG, ALT, $\mathrm{ALT}^{2}, \mathrm{ASR}, \mathrm{ASR}^{2}, \mathrm{HD}, \mathrm{HD}^{2}, \mathrm{HD} \times \mathrm{VEG}, \mathrm{OD}, \mathrm{OD}^{2}$, and $\mathrm{OD} \times \mathrm{VEG}$ (Ecological Archives E092-123-A12).

\section{APPENDIX M}

Model selection summary for indigenous species richness at the site scale (metacommunity), with predictor variables VEG, ALT, $\mathrm{ALT}^{2}, \mathrm{ASR}, \mathrm{ASR}^{2}, \mathrm{HD}, \mathrm{HD}^{2}, \mathrm{HD} \times \mathrm{VEG}, \mathrm{OD}, \mathrm{OD}^{2}$, and $\mathrm{OD} \times \mathrm{VEG}($ Ecological Archives E092-123-A13).

\section{APPENDIX N}

Model selection summary for indigenous species richness at the sample scale (neighborhood interaction) with predictor variables $\mathrm{VEG}, \mathrm{ALT}, \mathrm{ALT}^{2}, \mathrm{ASR}, \mathrm{ASR}^{2}, \mathrm{HD}, \mathrm{HD}^{2}, \mathrm{HD} \times \mathrm{VEG}, \mathrm{OD}, \mathrm{OD}^{2}$, and $\mathrm{OD} \times \mathrm{VEG}($ Ecological Archives $\mathrm{E} 092-123-\mathrm{A} 14)$. 